\title{
Removal of Zn (II) from Aqueous Solution onto Kaolin by Batch Design
}

\author{
Bahia Meroufel ${ }^{1,2,3^{*}}$, Omar Benali ${ }^{4}$, Mohamed Benyahia ${ }^{2}$, Mohamed Amine Zenasni ${ }^{1,3}$, \\ André Merlin ${ }^{3}$, Béatrice George ${ }^{3}$ \\ ${ }^{1}$ Laboratory of Valorisation of Vegetal Resources and Food Security (VRVSA), Bechar University, Bechar, Algeria \\ ${ }^{2}$ Department of Chemistry, Faculty of Sciences, Djillali Liabes University, Sidi Bel Abbes, Algeria \\ ${ }^{3}$ Laboratory of Studies and Research on Material Wood (LERMAB), University of Lorraine, Nancy, France \\ ${ }^{4}$ Department of Chemistry, Faculty of Sciences, Tahar Moulay University, Saida, Algeria \\ Email: ${ }^{*}$ b.meroufel@gmail.com
}

Received April 26, 2013; revised May 28, 2013; accepted June 18, 2013

Copyright (C) 2013 Bahia Meroufel et al. This is an open access article distributed under the Creative Commons Attribution License, which permits unrestricted use, distribution, and reproduction in any medium, provided the original work is properly cited.

\begin{abstract}
The Algerian kaolin clay was investigated to remove Zn(II) heavy metal ion from aqueous solution. The effect of contact time, initial metal ion concentration, $\mathrm{pH}$ and temperature was experimentally studied in batch mode to evaluate the adsorption capacity, kinetic, thermodynamic and equilibrium. The extent of zinc adsorption increased with increasing initial concentration of adsorbat, $\mathrm{pH}$ and temperature. The linear Langmuir and Freundlich models were applied to describe equilibrium isotherms and both models fitted well. The monolayer adsorption capacity for $\mathrm{Zn}$ (II) ions was 12.23 $\mathrm{mg}$ per g of kaolin clay at $\mathrm{pH} 6.1$ and $25^{\circ} \mathrm{C}$. Dubinin-Radushkevich (D-R) isotherm model was also applied to the equilibrium data. Thermodynamic parameters showed that the adsorption of $\mathrm{Zn}$ (II) onto kaolin clay was spontaneous and endothermic process in nature. Furthermore, the Lagergren-first-order and pseudo-second-order models were used to describe the kinetic data. The experimental data fitted well the pseudo-second-order kinetic. As a result, the kaolin clay may be used for removal of zinc from aqueous media.
\end{abstract}

Keywords: Zn(II); Kaolin; Adsorption Isotherm; Thermodynamic; Kinetic

\section{Introduction}

Heavy metal contamination has become an environmental problem today in both developing and developed countries throughout the world [1,2]. Heavy metals are of considerable environmental concern due to their toxicity, wide sources, non-biodegradable properties and accumulative behaviours [3].

Zinc is considered as an essential element for life and acts as a micronutrient when presented in trace amounts. But too much zinc can be harmful to health. $\mathrm{Zn}$ (II) is reported to be toxic beyond permissible limits. Symptoms of zinc toxicity include irritability, muscular stiffness, loss of appetite and nausea [4]. WHO [5] recommended level of zinc in drinking water is $5 \mathrm{mg} / \mathrm{L}$. The metal is further reported to be bioaccumulated into flora and fauna creating ecological problems. In developing countries, metal mining and metallurgy industrial departments produce large quantities of wastewater containing high concentration of $\mathrm{Zn}$ (II) [6,7]. It is also present in high

"Corresponding author. concentration in wastewater of pharmaceuticals, galvanizing, paints, pigments, insecticides, cosmetics, etc. that causes serious problem to the environment [8]. Therefore, the heavy metal levels in wastewater, drinking water, and water used for agriculture should be reduced to the maximum permissible concentration. Many methods such as ion exchange, precipitation, membrane processes and reverse osmosis have been used for the removal of toxic metal ions [9-15]. However, these methods have several disadvantages such as incomplete metal ion removal, high reagent and energy requirements, generation of toxic sludge or other waste products, and long desorption time. Adsorption is recognized as an effective and economic method for removal of pollutants from wastewaters. In recent years, many studies have focused on seeking cheap, locally available and effective adsorbents, such as waste biopolymers, clays and clay minerals [16].

Clay minerals are low-cost and readily available materials functioning as excellent cation exchangers, which have often been used to adsorb metallic contaminants. 
They have different adsorption capacities for metal ions, such as mesoporous silica [17] and montmorillonite clay $[18,19]$. Kaolinite clay is a 1:1 clay mineral including a tight interlayer structure with the ideal formula of $\mathrm{Al}_{2} \mathrm{Si}_{2} \mathrm{O}_{5}(\mathrm{OH})_{4}[20,21]$. The sorption properties of this clay are solely determined by the nature of its surface and edges. Kaolinite clay possesses a variable charge that can be related to the reactions between ionisable surface groups located at the edges and the ions present in aqueous solution $[20,22]$. It has been used as adsorbent material for the adsorption process of various heavy metals [23-26].

The objective of the present work is to study the adsorption characteristics of $\mathrm{Zn}$ (II) ions from aqueous solution using Algerian kaolin clay. The influences of adsorption conditions such as contact time, $\mathrm{pH}$ changes, initial concentration of $\mathrm{Zn}(\mathrm{II})$ ions and temperature effect were investigated. In addition, the evidence for physicochemical characteristics of Algerian kaolin clay obtained from X-ray diffraction (XRD) and scanning electron microscope (SEM) was investigated to understand the adsorption mechanism. Finally, kaolin clay potentially used to remove $\mathrm{Zn}$ (II) metal ion in wastewater was demonstrated.

\section{Materials and Methods}

\subsection{Adsorbent}

The kaolin sample used in this investigation was collected from a natural deposit, located in Tabelbala in province Bechar (Algeria). The surface area and CEC of kaolin were measured using methylene blue technique [27]. The sample of kaolin powder was characterized by using infrared (FT-IR), X-ray diffraction (XRD) and scanning electron microscopic (SEM) techniques.

\subsection{Reagents}

All chemicals used were of analytical grade. Stock standard solution of $\mathrm{Zn}^{2+}$ has been prepared by dissolving the appropriate amount of $\mathrm{ZnSO}_{4} \cdot 7 \mathrm{H}_{2} \mathrm{O}$ in deionized water. This stock solution was then diluted to specified concentrations. The $\mathrm{pH}$ of the system was adjusted using reagent grade $\mathrm{NaOH}$ and $\mathrm{HCl}$ respectively. All plastic sample bottles and glassware were cleaned, then rinsed with deionized water and dried at $60^{\circ} \mathrm{C}$ in a temperature controlled oven.

\subsection{Instrumentation}

The $\mathrm{pH}$ of all solution was measured by a TitraLab Instrument TIM800 Model $\mathrm{pH}$ meter. The adsorption experiments have been studied by batch technique using a thermostated shaker bath GFL-1083 Model. A Eppendorf
5702 Model digital centrifuge was used to centrifuge the samples. Zn(II) concentrations of solutions before and after adsorption were measured by using flame atomic absorption spectrophometer (Varian, SpectrAA-100, AAS).

The Fourier transform infrared (FT-IR) absorption spectra was recorded on $\mathrm{KBr}$ pressed pellets of the powdered sample in the range $4000-400 \mathrm{~cm}^{-1}$, using a Perkine-Elmer FTIR 2000 spectrophotometer.

The X-ray diffraction pattern of powder was recorded on a Phillips-1730 (PAN analytical) X-ray diffractometer using $\mathrm{Cu} \mathrm{K} \alpha$ radiation $(\lambda=1.54 \AA)$.

Nanomorphology was characterized by scanning electron microscopy (SEM) witch was carried out using Hitachi S-4800 equipped with energy dispersive spectrometry for chemical analysis (EDS) and operating at 15 $\mathrm{kV}$ acceleration voltage.

\subsection{Adsorption Procedure}

Adsorption measurements were determined by batch experiments. The effect of contact time on the adsorption capacity of Kaolin was studied in the range $1-360 \mathrm{~min}$ at an initial concentration of $100 \mathrm{mg} / \mathrm{L}$. Adsorption kinetics was studied using an initial concentration of 100 $\mathrm{mg} / \mathrm{L}$ with the adsorbent dosage of $0.2 \mathrm{~g} / 20 \mathrm{~mL}$ at $\mathrm{pH} 6.1$. Adsorption isotherms were studied at various initial concentrations of $\mathrm{Zn}$ (II) ion in the range of $10-120 \mathrm{mg} / \mathrm{L}$ and the experiments were conducted at different constant temperatures in the range $25^{\circ} \mathrm{C}-60^{\circ} \mathrm{C}$. The amount of $\mathrm{Zn}$ (II) adsorbed per unit mass of kaolin was calculated by using the mass balance equation given in Equation (1) [28].

$$
q_{e}=\frac{\left(C_{o}-C_{e}\right) V}{m}
$$

where $q_{e}$ is the maximum adsorption capacity in $\mathrm{mg} / \mathrm{g}, C_{o}$ is the initial concentration and $C_{e}$ is the concentration at equilibrium of $\mathrm{Zn}$ (II) solution in $\mathrm{mg} / \mathrm{L}, V$ is the volume of the $\mathrm{Zn}(\mathrm{II})$ solution in $\mathrm{mL}$ and $m$ is the mass of the kaolin in grams.

The percent adsorption of metal ion was calculated as follows Equation (2) [24]:

$$
\text { Sorption } \%=\frac{C_{o}-C_{e}}{C_{o}} \times 100 \%
$$

The sorption capacity at time $t, q_{t}(\mathrm{mg} / \mathrm{g})$ was obtained as Equation (3) [24]:

$$
q_{t}=\frac{\left(C_{o}-C_{e}\right) V}{m}
$$

where $C_{o}$ and $C_{t}(\mathrm{mg} / \mathrm{L})$ are the liquid phase concentrations of $\mathrm{Zn}$ (II) at initial and a given time $t, V$ is the solution volume and $\mathrm{m}$ the mass kaolin $(\mathrm{g})$. 


\section{Results and Discussion}

\subsection{Characterisation of Adsorbent}

SEM micrograph of the untreated clay sample suggests a very cohesive material (Figure 1). The micrograph confirms that the material is forming micron-size agglomerates. A higher magnification micrograph of the same structure shows that the micro-size particles are composed of individual platelets, which conglomerate into larger size particles.

The X-ray diffraction spectrograph of the kaolin clay is shown in Figure 2. Kaolin show three intense diffraction peaks at $2 \theta$ value of $12.4^{\circ}, 24.8^{\circ}$ and $26.6^{\circ}$, less intense peaks at $2 \theta$ of $36.7^{\circ}, 39.6^{\circ}, 48.0^{\circ}, 50.1^{\circ}$ and $60.1^{\circ}$ and humps at $2 \theta=19.8^{\circ}-21.9^{\circ}, 37.8^{\circ}-39.2^{\circ}$ and $44.8^{\circ}-$ $46.9^{\circ}$, which are all associated with kaolinite $(\mathrm{K})$. Diffraction peaks of quartz (Q) could be found at $2 \theta$ values of $20.9^{\circ}, 26.4^{\circ}, 50.9^{\circ}, 62.3^{\circ}$ and $68.1^{\circ}$. Illite (I) was also detected at $2 \theta=17.9^{\circ}, 30.2^{\circ}, 35.1^{\circ}, 42.4^{\circ}$ and $55^{\circ}$.

The FTIR Spectra of the kaolin, in the range of 400 $4000 \mathrm{~cm}^{-1}$ was taken to confirm the presence of functional groups that might be responsible for the adsorption process and presented in Figure 3. As may be seen, clay display a number of adsorption peaks, reflecting the complex nature the kaolin clay. The main bonds observed

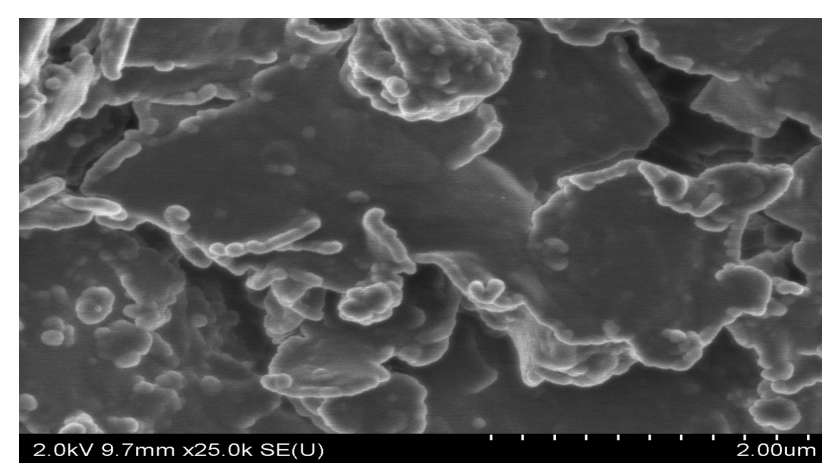

Figure 1. SEM of kaolin clay.

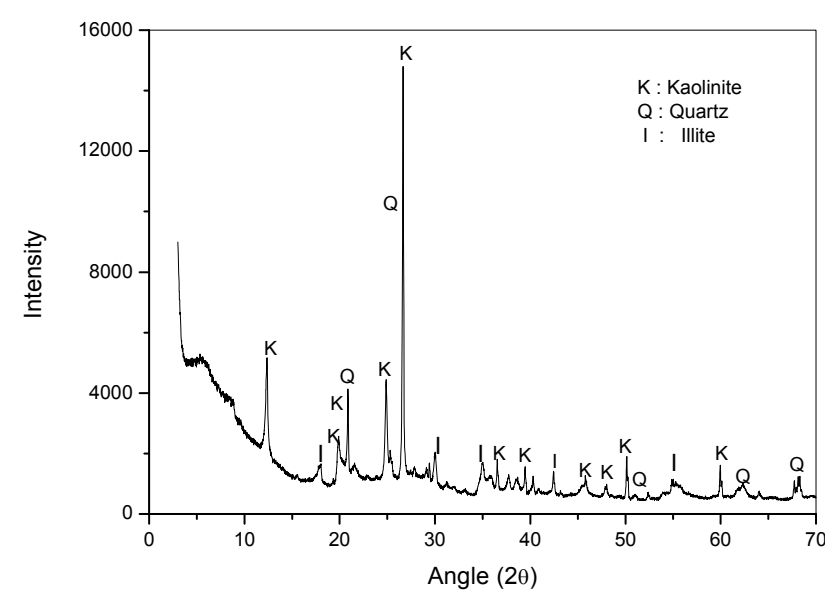

Figure 2. XRD pattern of kaolin. were $\mathrm{OH}^{-}$stretching, hydroxyl sheet at $3698 \mathrm{~cm}^{-1}$ and $3620 \mathrm{~cm}^{-1} \cdot \mathrm{H}_{2} \mathrm{O}$ stretching was also found at $1636 \mathrm{~cm}^{-1}$. Bands at $1033 \mathrm{~cm}^{-1}$ and $984 \mathrm{~cm}^{-1}$ were assigned to $\mathrm{Si}-\mathrm{O}$ bonds in the $\mathrm{SiO}_{4}$ molecules [29]. The other band at 913 $\mathrm{cm}^{-1}$ was attributed to $\mathrm{Al}^{\mathrm{IV}}-\mathrm{OH}$ vibrations [30]. The bands at $798 \mathrm{~cm}^{-1}, 750 \mathrm{~cm}^{-1}$ and $694 \mathrm{~cm}^{-1}$ were Si-O symmetric stretching [31]. Absorption at $535 \mathrm{~cm}^{-1}$ was assigned as $\mathrm{Si}-\mathrm{O}-\mathrm{Al}^{\mathrm{VI}}$, where the $\mathrm{Al}$ is in octahedral coordination [30,31].

The average surface area and CEC (Cation Exchange Capacity) of kaolin which were measured using methylene blue technique [27] were $10.60 \mathrm{~m}^{2} / \mathrm{g}$ and $8.01 \mathrm{meq} /$ $100 \mathrm{~g}$, respectively.

\subsection{Effect of Contact Time}

The effect of contact time on the adsorption of $\mathrm{Zn}$ (II) ion onto kaolin clay at $25^{\circ} \mathrm{C}$ and pH 6.1 is shown in Figure 4. It can be seen that the adsorption of $\mathrm{Zn}$ (II) occurred very quickly from the beginning of the experiment to the first $12 \mathrm{~min}$. where the maximum adsorption of $\mathrm{Zn}$ (II) onto clay was observed; it can be said that beyond this there

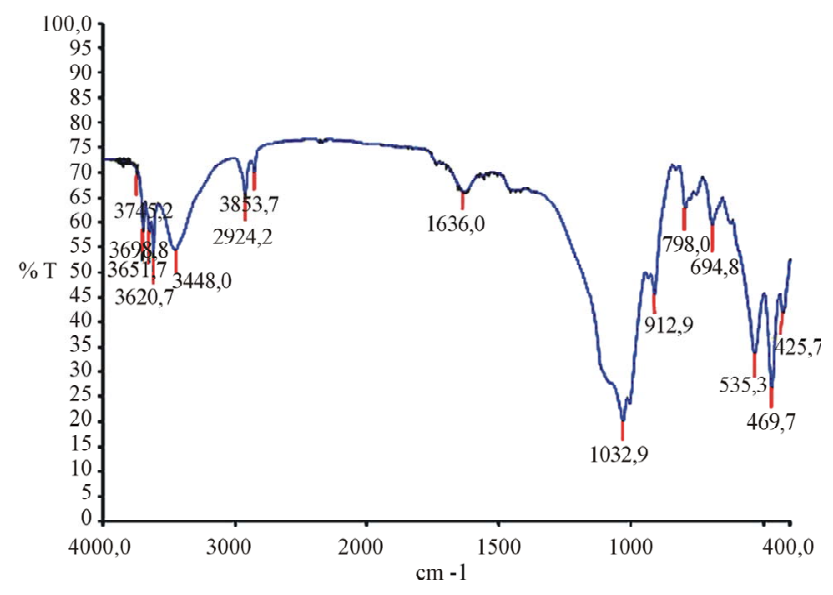

Figure 3. IR spectra of kaolin.

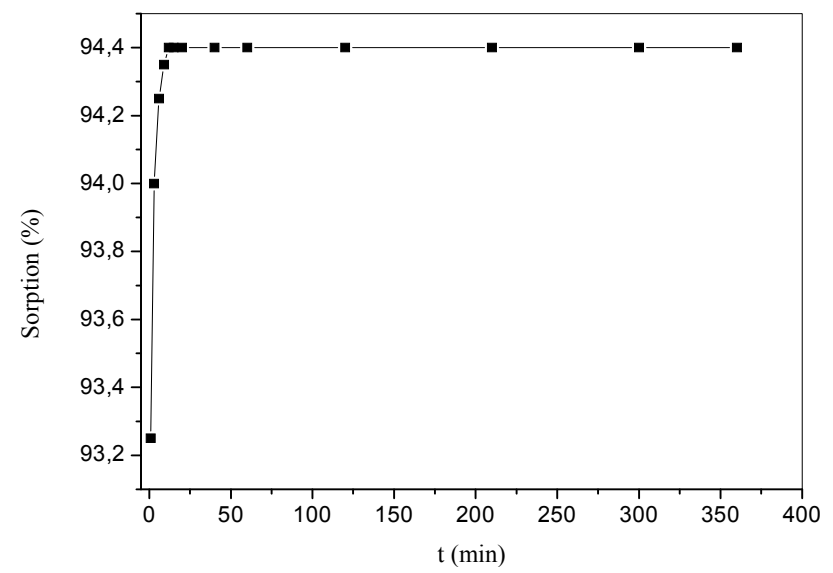

Figure 4. Effect of contact time on adsorption capacity of Kaolin. 
was almost no further increase in the adsorption. This was due to the decrease of adsorption sites on the clay which gradually interacted with the metal ion [32]. Therefore, 12 min was selected as the optimum contact time for all further experiments.

In this study, $94.4 \%$ of $\mathrm{Zn}(\mathrm{II})$, were adsorbed on the Kaolin clay when the equilibrium was reached in just 12 min. On the basis of this result, it can be observed that natural kaolin clay can be used to remove this metal ion.

\subsection{Effect of Initial Concentration of Zn (II)}

Effect of initial concentration of $\mathrm{Zn}$ (II) on adsorption capacity of kaolin was investigated by varying initial concentration of $\mathrm{Zn}(\mathrm{II})$ from 10 to $120 \mathrm{mg} / \mathrm{L}$. For this study, $\mathrm{pH}$, temperature, adsorbent dosage and contact time have been fixed as $25^{\circ} \mathrm{C}, 0.2 \mathrm{~g} / 20 \mathrm{~mL}$ and $12 \mathrm{~min}$. The results are presented in Figure 5. An increase of $\mathrm{Zn}$ (II) concentration accelerates the diffusion of $\mathrm{Zn}$ (II) ions from solution to the adsorbent surface due to the increase in driving force of concentration gradient. Hence, the amount of adsorbed $\mathrm{Zn}$ (II) at equilibrium increased from 0.98 to $10.44 \mathrm{mg} / \mathrm{g}$ as the $\mathrm{Zn}(\mathrm{II})$ concentration is increased from 10 to $120 \mathrm{mg} / \mathrm{L}$.

\subsection{Effect of pH}

Effect of initial $\mathrm{pH}$ on the adsorption capacity of kaolin for $\mathrm{Zn}$ (II) was studied by varying solution $\mathrm{pH}$ from 1.5 to 11 at the adsorbent dosage of $0.2 \mathrm{~g} / 20 \mathrm{~mL}$ using an initial concentration of $\mathrm{Zn}(\mathrm{II})$ as $100 \mathrm{mg} / \mathrm{L}$. The $\mathrm{pH}$ range of 1.5 - 6.1 was chosen, as the precipitation of $\mathrm{Zn}(\mathrm{II})$ is found to occur at $\mathrm{pH} \geq 7$ [16]. Variation of adsorption capacity of kaolin for $\mathrm{Zn}$ (II) ions with $\mathrm{pH}$ is shown in Figure 6. It is evident that the adsorption of $\mathrm{Zn}$ (II) ions on kaolin is strongly dependant on the $\mathrm{pH}$ of the solution. The adsorption of $\mathrm{Zn}$ (II) ions increases steadily with increase in

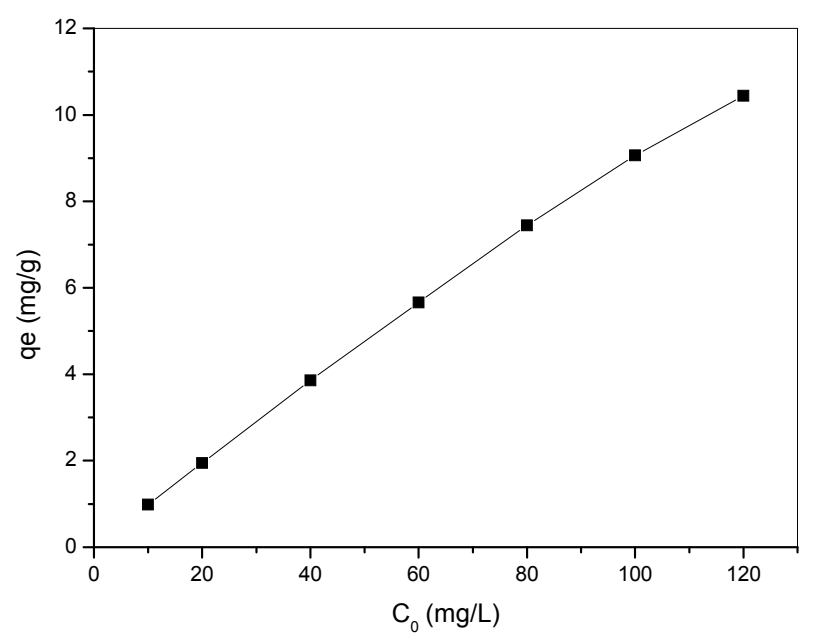

Figure 5. Effect of initial concentration of $\mathrm{Zn}(\mathrm{II})$ on adsorption capacity of Kaolin.

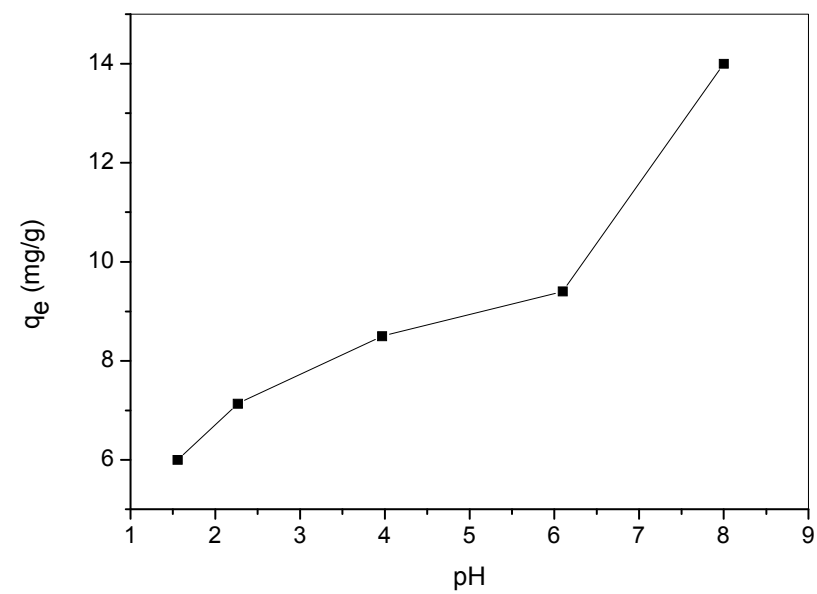

Figure 6. Effect of pH on adsorption capacity of Kaolin.

initial $\mathrm{pH}$ from 1.5 to 6.1 and the maximum adsorption capacity of $9.4 \mathrm{mg} / \mathrm{g}$ is observed at $\mathrm{pH} 6.1$ (natural $\mathrm{pH}$ of suspension).

The effect of $\mathrm{pH}$ can be explained considering the surface charge on the adsorbent material. At low $\mathrm{pH}$ values ( $\mathrm{pH} 2-6)$, the low adsorption observation was explained due to increase in positive charge (protons) density on the surface sites and thus, electrostatic repulsion occurred between the metal ions $\left(\mathrm{M}^{2+}: \mathrm{Zn}^{2+}\right)$ and the edge groups with positive charge $\left(\mathrm{Si}-\mathrm{OH}^{2+}\right)$ on the surface as follows:

$$
-\mathrm{SiOH}+\mathrm{H}^{+} \rightarrow-\mathrm{SiOH}^{2+}+\mathrm{H}^{-}
$$

In an alkaline medium $(\mathrm{pH}>7)$, the surface of kaolin clay becomes negatively charged and electrostatic repulsion decreases with raising $\mathrm{pH}$ due to reduction of positive charge density on the sorption edges thus resulting in an increase metal adsorption. This mechanism can be shown as follows:

$$
\begin{gathered}
-\mathrm{SiOH}+\mathrm{H}^{+} \rightarrow-\mathrm{SiO}^{-}+\mathrm{H}_{2} \mathrm{O} \\
-\mathrm{SiO}^{-}+\mathrm{M}^{2+} \rightarrow-\mathrm{SiOM}^{2+}
\end{gathered}
$$

A similar theory was proposed by several earlier workers for metal adsorption on different adsorbents [6, 33].

\subsection{Adsorption Isotherm Models}

Three important isotherm models were selected in this study, which are namely the Langmuir, Freundlich and Dubinin-Radushkevich (D-R) isotherm models.

\subsubsection{Langmuir Isotherm Model}

Langmuir isotherm model was applied to establish the relationship between the amount of $\mathrm{Zn}$ (II) adsorbed onto kaolin clay and its equilibrium concentration in aqueous solution. Langmuir adsorption isotherm [34] is applied to equilibrium adsorption assuming monolayer adsorption onto a surface with a finite number of identical sites and 
is represented in linear form

$$
\frac{C_{e}}{q_{e}}=\frac{C_{e}}{q_{m}}+\frac{1}{K_{L} q_{m}}
$$

where $C_{e}$ is equilibrium concentration of the metal $(\mathrm{mg} / \mathrm{L})$ and $q_{e}$ is the amount of the metal adsorbed (mg) by per unit of the adsorbent (g). $q_{m}$ and $K_{L}$ are Langmuir constant relating adsorption capacity $(\mathrm{mg} / \mathrm{g})$ and the energy of adsorption $(\mathrm{L} / \mathrm{g})$, respectively. These constants are evaluated from slope and intercept of the linear plots of $C_{e} / q_{e}$ versus $C_{e}$, respectively (Figure 7).

The Langmuir monolayer adsorption capacity of kaolin clay was estimated as $12.23 \mathrm{mg} / \mathrm{g}$ (Table $\mathbf{1}$ ).

Based on the further analysis of Langmuir equation, the dimensionless parameter of the equilibrium or adsorption intensity $\left(R_{L}\right)$ can be expressed by

$$
R_{L}=\frac{1}{1+K_{L} C_{0}}
$$

where $C_{0}(\mathrm{mg} / \mathrm{L})$ is the initial dye concentration and $K_{L}$ $(\mathrm{L} / \mathrm{mg})$ is the Langmuir constant related to the energy of adsorption. The value of $R_{L}$ indicates the shape of the isotherms to be either unfavourable $\left(R_{L}>1\right)$, linear $\left(R_{L}=\right.$ $1)$, favourable $\left(0<R_{L}<1\right)$ or irreversible $\left(R_{L}=0\right)$. The influence of isotherm shape on whether adsorption is favourable or unfavourable has been considered [35].

For a Langmuir type adsorption process, the isotherm shape can be classified by a dimension less constant separation factor $\left(R_{L}\right)$, given by Equation (8). The calculated $R_{L}$ values as different initial $\mathrm{Zn}$ (II) concentrations are shown in Figure 8. It was observed that the value of $R_{L}$ in the range 0 - 1 confirmed the favourable uptake of the $\mathrm{Zn}(\mathrm{II})$ process. Also lower $R_{L}$ values at higher initial $\mathrm{Zn}$ (II) concentrations showed that adsorption was more favourable at higher concentration. The degree of favourability is generally related to the irreversibility of the system, giving a qualitative assessment of the kaolin$\mathrm{Zn}$ (II) interactions. The degrees tended toward zero (the completely ideal irreversible case) rather than unity (which represents a completely reversible case).

\subsubsection{Freundlich Isotherm Model}

The equilibrium data was also applied to the Freundlich adsorption isotherm [36], which is the earliest relationship known describing the adsorption equilibrium and is expressed in linear form by the following equation:

$$
\ln q_{e}=\ln K_{F}+\left(\frac{1}{n}\right) \ln C_{e}
$$

where $K_{F}$ and n are Freundlich constants related to adsorption capacity and adsorption intensity, respectively. When $l n q_{e}$ is plotted against $l C_{e}$, a straight line with slope $\mathrm{n}$ and intercept $K_{F}$ is obtained (see Figure 9).

The intercept of the line, $K_{F}$, is roughly an indicator of the adsorption capacity and the slope, $\mathrm{n}$, is an indication of adsorption intensity. The values obtained for the Freundlich variables for the adsorption of $\mathrm{Zn}$ ions are given in Table 1.

A relatively slight slope $n<1$ indicates that adsorption intensity is good (or favorable) over the entire range of concentrations studied, while a steep slope $(n>1)$ means that adsorption intensity is good (or favorable) at high concentrations but much less at lower concentrations

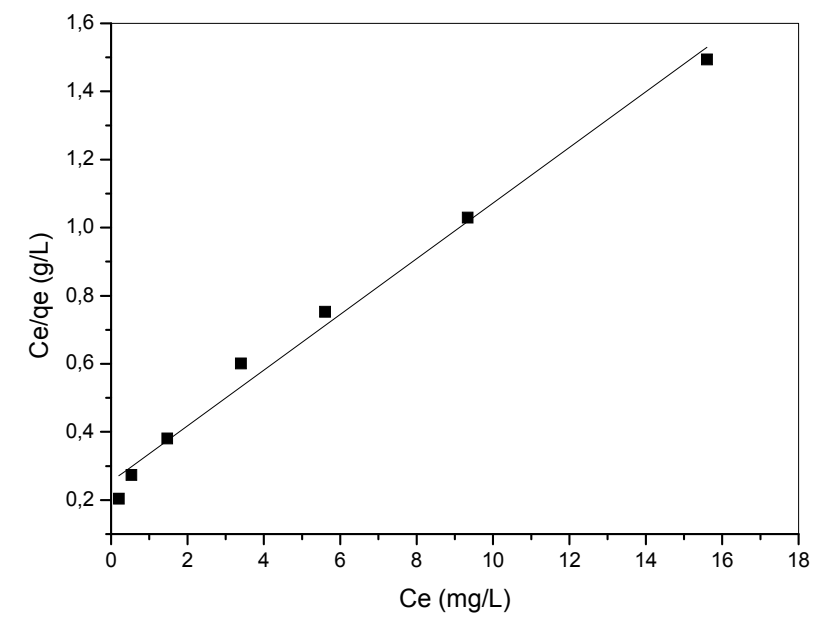

Figure 7. Langmuir isotherm plot for adsorption of $\mathrm{Zn}(\mathrm{II})$ on the Kaolin.

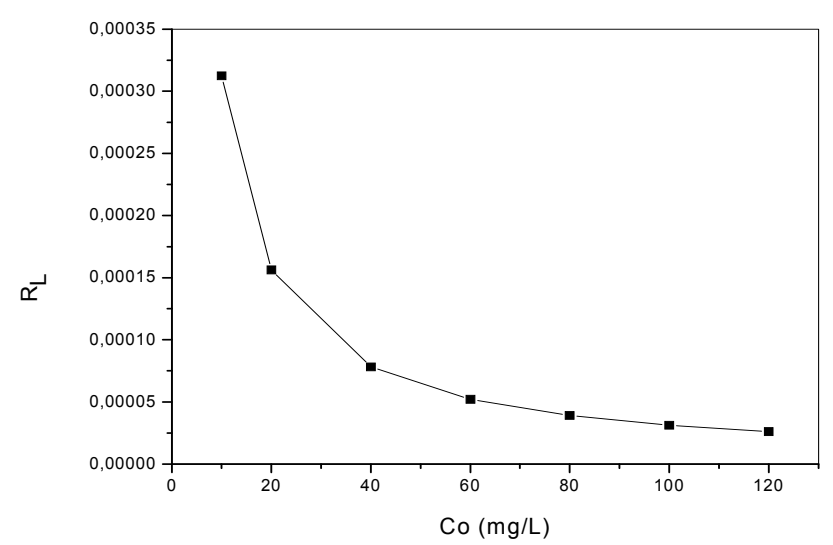

Figure 8. Plot of separation factor versus initial $\mathrm{Zn}$ (II) concentration.

Table 1. Langmuir, Freundlich and D-R isotherm parameters for the adsorption of Zn(II) onto Kaolin clay.

\begin{tabular}{ccccccccc}
\hline \multicolumn{2}{c}{ Langmuir isotherm constants } & \multicolumn{3}{c}{ Freundlich isotherm constants } & \multicolumn{3}{c}{ D-R isotherm constants } \\
\hline$q_{m}(\mathrm{mg} / \mathrm{g})$ & $K_{L}(\mathrm{~L} / \mathrm{g})$ & $\mathrm{R}^{2}$ & $n$ & $K_{F}$ & $\mathrm{R}^{2}$ & $q_{m}(\mathrm{mg} / \mathrm{g})$ & $E(\mathrm{~kJ} / \mathrm{mol})$ & $\mathrm{R}^{2}$ \\
12.23 & 0.32 & 0.988 & 1.82 & 2.7 & 0.981 & 2.51 & 2.14 & 0.80 \\
\hline
\end{tabular}




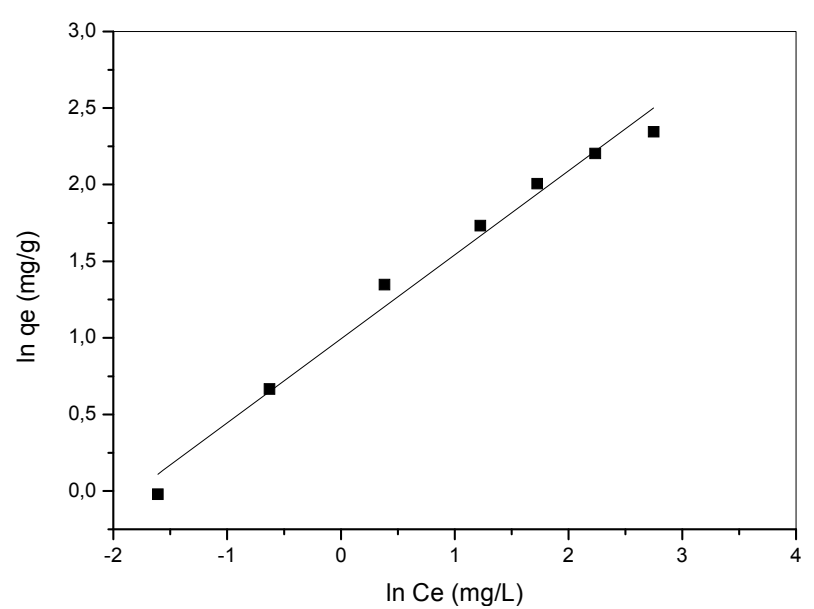

Figure 9. Freundlich isotherm plot for adsorption of $\mathrm{Zn(II)}$ on the Kaolin.

[37]. In the present study, the value of $n(n=1.82)$ is greater than 1 , indicating that the adsorption process is favourable. The $K_{F}$ value of the Freundlich equation also indicates that kaolin has a high adsorption capacity for zinc ions in aqueous solutions.

The value of correlation coefficient $\left(\mathrm{R}^{2}=0.981\right)$ is also good. It can be said that Freundlich model fitted well.

\subsubsection{Dubinin-Radushkevich (D-R) Model}

The adsorption data was also modeled by D-R isotherm to determinate the adsorption type (physical or chemical). The linear form of this model is expressed by [38-42].

$$
\ln q_{e}=\ln q_{m}-\beta \varepsilon^{2}
$$

where $q_{e}$ is the amount of the metal adsorbed onto per unit dosage of the adsorbent $(\mathrm{mol} / \mathrm{L}) ; q_{m}$, the monolayer adsorption capacity $(\mathrm{mol} / \mathrm{g}) ; \varepsilon$, the activity coefficient related to mean sorption energy $\left(\mathrm{mol}^{2} / \mathrm{J}^{2}\right)$ and $\varepsilon$ is the Polanyi potential.

$$
\varepsilon=R T \ln \left(1+\frac{1}{C_{e}}\right)
$$

A plot of $\ln q_{e}$ against $\varepsilon^{2}$ is given in Figure 10. D-R isotherm constant, $q_{m}$, for Kaolin clay was found to be $2.51 \mathrm{mg} / \mathrm{g}$ (Table 1). The difference of $q_{m}$ derived from the Langmuir and D-R models is large. The difference may be attributed to the different definition of $q_{m}$ in the two models. In Langmuir model, $q_{m}$ represents the maximum adsorption of metal ions at monolayer coverage, whereas it represents the maximum adsorption of metal ions at the total specific micropore volume of the adsorbent in D-R model. Thereby, the value of $q_{m}$ derived from Langmuir model is higher than that derived from $\mathrm{D}-\mathrm{R}$ model. The differences are also reported in previous studies $[19,38,40]$.

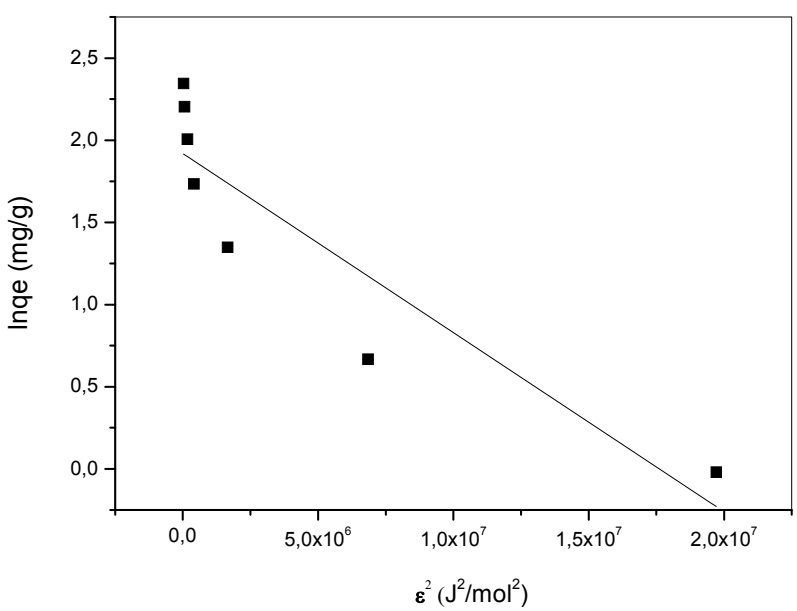

Figure 10. D-R isotherm plot for adsorption of $\mathrm{Zn}(\mathrm{II})$ on Kaolin.

The mean sorption energy $E(\mathrm{~kJ} / \mathrm{mol})$, can be calculated using the following equation (Equation (12)):

$$
E=\frac{1}{\sqrt{-2 \beta}}
$$

The adsorption is basically a surface adsorption associated with ion exchange when $|E|$ is between 8 and $16 \mathrm{~kJ}$ $\mathrm{mol}^{-1}$. Otherwise, for $|E|$ ranging from 1.0 to $8.0 \mathrm{~kJ} \mathrm{~mol}^{-1}$, the mechanism is physical adsorption [38-42]. The calculated value of $E$ is $2.14 \mathrm{~kJ} / \mathrm{mol}$ for Kaolin, and it is in the range of values for physical adsorption reactions. The similar results for the adsorption of $\mathrm{Zn}(\mathrm{II})$ was reported by earlier worker [42-44].

\subsection{Adsorption Kinetic Models}

In an attempt to present the kinetic equation representing adsorption of $\mathrm{Zn}(\mathrm{II})$ onto kaolin clay, two kinds of kinetic models were used to test the experimental data. These are Lagergren-first-order equation and secondorder equation.

Lagergren-first-order equation is the most popular kinetics equation. The form is

$$
\frac{\mathrm{d} q}{\mathrm{~d} t}=k_{1}\left(q_{e}-q_{t}\right)
$$

After definite integration by applying the conditions $q_{t}$ $=0$ at $t=0$ and $q_{t}=q_{t}$ at $t=t$, Equation (13) becomes the following $[45,46]$ :

$$
\ln \ln \left(q_{e}-q_{t}\right)=\ln q_{e}-k_{1} t
$$

where $q_{t}(\mathrm{mg} / \mathrm{g})$ is the amount of adsorption time $t(\mathrm{~min})$; $k_{1}$, the rate constant of the equation $\left(\mathrm{min}^{-1}\right)$ and $q_{e}$ is the amount of adsorption equilibrium $(\mathrm{mg} / \mathrm{g})$. The adsorption rate constant $k_{1}$, can be determined experimentally by plotting of $\ln \left(q_{e}-q_{t}\right)$ versus $t$ (see Figure 11).

The second-order equation is in the following form: 


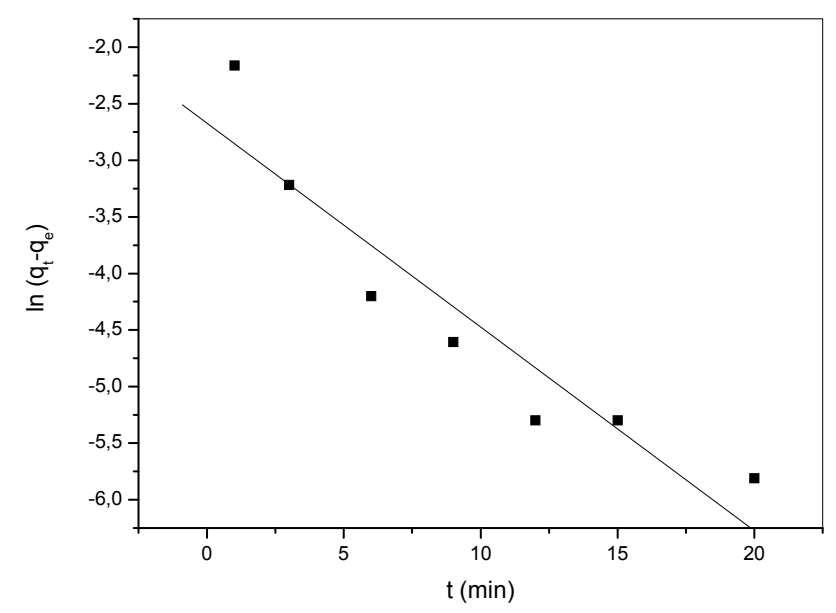

Figure 11. Lagergren pseudo first-order plots for Zn(II) adsorbed on kaolin.

$$
\frac{\mathrm{d} q}{\mathrm{~d} t}=k_{2}\left(q_{e}-q_{t}\right)^{2}
$$

After definite integration by applying the conditions $q_{t}$ $=0$ at $t=0$ and $q_{t}=q_{t}$ at $t=t$, Equation (15) becomes the following [47-49]:

$$
\frac{t}{q_{t}}=\frac{1}{2 k q_{e}^{2}}+\frac{1}{q_{e}} t
$$

where $q_{t}(\mathrm{mg} / \mathrm{g})$ is the amount of adsorption time $t$ ( $\left.\mathrm{min}\right)$, $k_{2}(\mathrm{~g} / \mathrm{mg} \mathrm{min})$ is the rate constant of the second-order equation and $q_{e}$ is the amount of adsorption equilibrium $(\mathrm{mg} / \mathrm{g})$.

$k_{2}$ and $q_{e}$ can be determined experimentally by plotting of $\mathrm{t} / q_{t}$ versus $t$ (Figure 12).

Based on the correlation coefficients presented in Table 2, the adsorption of $\mathrm{Zn}$ (II) onto Algerian kaolin was best described by the second order equation. A good agreement with this adsorption model was confirmed by the similar values of $\mathrm{q}_{\mathrm{e}}$ experimental and $\mathrm{q}_{\mathrm{e}}$ calculated. Many studies reported the first-order equation of Lagergren does not fit well to the initial stages of the adsorption processes $[42,45,50,51]$. The first-order kinetic process has been used for reversible reaction with an equilibrium being established between liquid and solid phases. In many cases, the second-order equation correlates well to the adsorption studies $[43,50]$.

The best fit to the pseudo-second order kinetic indicated that the adsorption mechanism depended on the adsorbate and adsorbent $[52,53]$.

\subsection{Thermodynamic of Adsorption}

Adsorption experiments to study the effect of temperature were carried out from $25^{\circ} \mathrm{C}$ to $60^{\circ} \mathrm{C}$ at optimum $\mathrm{pH}$ value of 6.1 and adsorbent dosage level of $0.1 \mathrm{~g} \cdot \mathrm{L}^{-1}$. The contact time for adsorption was maintained at $12 \mathrm{~min}$. The variation in the extent of adsorption with respect to temperature has been explained based on thermodynamic parameters viz. free energy change $(\Delta G)$, enthalpy change $(\Delta H)$ and entropy change $(\Delta S)$ which were determined using the following equations [54]:

$$
\begin{gathered}
K_{d}=\frac{q_{e}}{C_{e}} \\
\ln K_{d}=\frac{\Delta S}{R}-\frac{\Delta H}{R T} \\
\Delta G=\Delta H-T \Delta \mathrm{S}
\end{gathered}
$$

when $\ln K_{d}$ was plotted against $1 / T$, (Figure 13), a straight line with the slope of $\Delta H / T$ and intercept of $\Delta S / R$ were obtained. The values of $\Delta H$ and $\Delta S$ were obtained from the slope and intercept of the Van't Hoff plots. The thermodynamic parameters for the adsorption process are given in Table 3.

It is clear that positive value of $\Delta H$ suggested the endothermic nature of the adsorption and the negative value of $\Delta G$ indicated the spontaneous nature of the adsorption process. Generally, the change in adsorption enthapy for

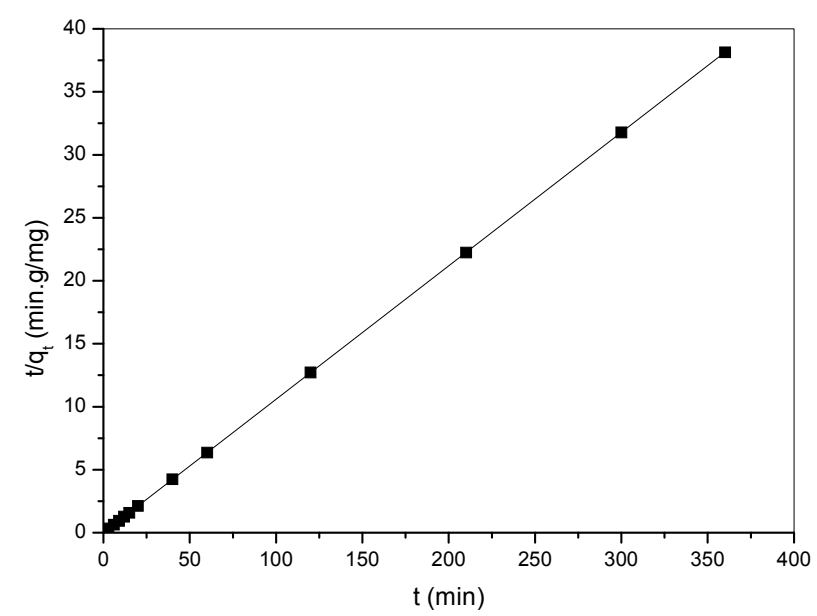

Figure 12. Pseudo second-order plots for Zn(II) adsorbed on kaolin.

Table 2. Comparison of adsorption rate constants, experimental and calculated $q_{\mathrm{e}}$ values for the pseudo-first and second order reaction kinetics for removal of zinc by kaolin clay.

\begin{tabular}{ccccccc}
\hline$q_{e}$ experimental $\left(\mathrm{mg} \cdot \mathrm{g}^{-1}\right)$ & \multicolumn{3}{c}{ Pseudo-first order } & \multicolumn{3}{c}{ Pseudo-second order } \\
\hline & $k_{1}\left(\mathrm{~min}^{-1}\right)$ & $q_{e}$ calculated $\left(\mathrm{mg} \cdot \mathrm{g}^{-1}\right)$ & $\mathrm{R}^{2}$ & $k_{2}\left(\mathrm{~g} \cdot \mathrm{mg}^{-1} \cdot \mathrm{min}^{-1}\right)$ & $q_{e}$ calculated $\left(\mathrm{mg} \cdot \mathrm{g}^{-1}\right)$ & $\mathrm{R}^{2}$ \\
9.44 & 0.18 & 0.07 & 0.855 & 11.33 & 9.44 & 1 \\
\hline
\end{tabular}


Table 3. Thermodynamic parameters.

\begin{tabular}{rrrrrrrr}
\hline & \multicolumn{1}{c}{$-\Delta G\left(\mathrm{KJ} \cdot \mathrm{mol}^{-1}\right)$} & & $\Delta H\left(\mathrm{KJ} \cdot \mathrm{mol}^{-1}\right)$ & $\Delta S\left(\mathrm{~J} \cdot \mathrm{mol}^{-1} \cdot \mathrm{K}^{-1}\right)$ & \\
\hline $25^{\circ} \mathrm{C}$ & $30^{\circ} \mathrm{C}$ & $40^{\circ} \mathrm{C}$ & $50^{\circ} \mathrm{C}$ & $60^{\circ} \mathrm{C}$ & & $\mathrm{R}^{2}$ \\
0.34 & 0.94 & 2.14 & 3.34 & 4.54 & 35.42 & 0.12 & 0.96 \\
\hline
\end{tabular}

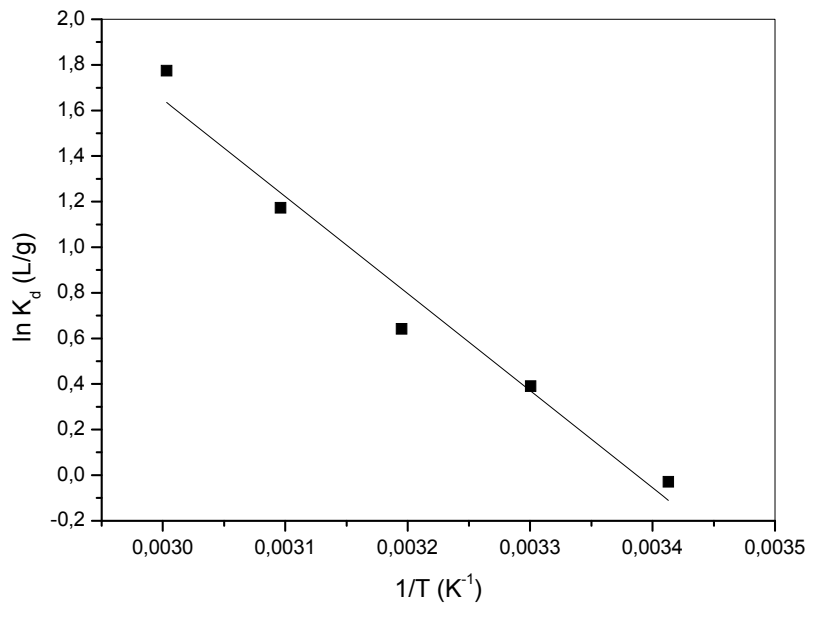

Figure 13. Plot of $\ln K_{d}$ against $1 / T$ for the adsorption of Zn(II) on kaolin.

physisorption is in the range of -20 to $40 \mathrm{~kJ} \mathrm{~mol}^{-1}$, but chemisorption is between -400 and $-80 \mathrm{~kJ} \mathrm{~mol}^{-1}[53,55]$. The value of adsorption heat showed that physical adsorption took place in the adsorption of $\mathrm{Zn}$ (II) ion on kaolin. Similar results were found for the adsorption of zinc on natural and $\mathrm{MnO}_{2}$ modified diatomite and on crosslinked starch Phosphates [56,57].

The slightly positive $\Delta S$ value showed the increased randomness at the solid/solution interface during the adsorption process. The adsorbed water molecules, which were displaced by the adsorbate species, gained more translational energy than was lost by the adsorbate ions, thus allowing the prevalence of the randomness in the system. Enhancement of the adsorption capacity at higher temperatures may be attributed to the enlargement of pore size and/or activation of the adsorbent surface [58, 59].

\subsection{Comparison of Kaolin Clay with Various Adsorbents for Zn(II) Removal}

The adsorption capacity of the kaolin clay for the removal of $\mathrm{Zn}$ (II) was compared with those of other adsorbents reported in literature and the values of adsorption capacities were presented in Table 4. The values reported in the form of monolayer adsorption capacity. The experimental data of the present investigation was comparable with the reported values. The kaolin clay had a high adsorption capacity as comparable with that of the other adsorbents. Therefore, considering the low cost of
Table 4. Comparison of adsorption capacity of kaolin clay with various adsorbents for $\mathrm{Zn}$ (II) removal.

\begin{tabular}{|c|c|c|}
\hline Adsorbent Adsorption & capacity $(\mathrm{mg} / \mathrm{g})$ & Reference \\
\hline Active carbon & 11.24 & {$[60]$} \\
\hline Kaolinite & 3.05 & [60] \\
\hline Bentonie & 9.12 & {$[60]$} \\
\hline Penicilliumchrysogenum & 11.11 & [61] \\
\hline Tannic acid immobilized & 1.23 & {$[62]$} \\
\hline $\begin{array}{l}\text { Groundnut shells (undyed } \\
\text { and dyed with C.I. }\end{array}$ & 7.62 (undyed), & [63] \\
\hline Reactive Orange 13) & 9.57 (dyed) & [63] \\
\hline Carbon aerogel & 1.183 & [64] \\
\hline Sugar beat pulp & 0.176 & {$[65]$} \\
\hline Fly ash & 11.11 & [65] \\
\hline Low rank Turkish coal & 1.66 & [66] \\
\hline Low-grade phosphate & 10.32 & [67] \\
\hline Activated alumina & 13.69 & [68] \\
\hline Clarified sludge & 15.53 & [68] \\
\hline Streptoverticillium & 9.15 & [61] \\
\hline Humic acid & 6.12 & [69] \\
\hline Amphibolite & 11.5 & {$[70]$} \\
\hline Granite & 8.64 & [70] \\
\hline Zeolite & 13.2 & [71] \\
\hline Sawdust & 2.58 & {$[72]$} \\
\hline Brine sediments & 4.85 & [72] \\
\hline kaolin clay & 12.23 & Present work \\
\hline
\end{tabular}

this natural adsorbent, it can be used as an alternative material to minimize the concentration of $\mathrm{Zn}$ (II) in wastewater.

\section{Conclusions}

The results of present investigation show that kaolin, low cost material, has suitable adsorption capacity with regard to the removal of zinc ions from its aqueous solutions. The adsorbed amount of $\mathrm{Zn}$ (II) ions increased with increase in initial concentration of adsorbat, $\mathrm{pH}$ and temperature. Experimental results were evaluated with Lang- 
muir, Freundich and Dubinin-Radushkevich isotherms. In addition to higher values of correlation coefficients, monolayer capacities $\left(q_{m}\right)$ determined from Langmuir isotherm and adsorption intensity $(n)$ determined from Freundlich isotherm indicate appropriateness of Langmuir and Freundlich isotherms for zinc metal. Pseudosecond-order reaction kinetic has provided a realistic description for removal of $\mathrm{Zn}^{2+}$ with similar values of $q_{e}$ calculated and $q_{e}$ experimental, whereas in the first order kinetic the difference between these values is large. The correlation coefficient was also higher in pseudo-secondorder kinetic.

The enthalpy change for the adsorption process was indicative of the endothermic nature of adsorption. The dimensionless separation factor $\left(R_{L}\right)$ showed that kaolin can be used for removal of zinc ions from aqueous solutions. The results of this research were compared to the published data in the same field, and found to be in agreement with most of them. The batch design may be useful for environmental technologist in designing treatment plants for metal removal from wastewaters.

\section{REFERENCES}

[1] L. P. Zhang, X. Ye, H. feng, Y. H. Jing, T. Ouyang, X. T. Yu, R. R. Liang, C. T. Gao and W. Q. Chen, "Heavy Metal Contamination in Western Xiamen Baysediments and Its Vicinity," Marine Pollution Bulletin, Vol. 54, No. 7, 2007, pp. 974-982. doi:10.1016/j.marpolbul.2007.02.010

[2] Y. B. Sun, Q. X. Zhou, X. K. Xie and R. Liu, "Spatial Sources and Risk Assessment of Heavy Metal Contamination of Urban Soils in Typical Regions of Shenyang," Journal of Hazardous Materials, Vol. 174, No. 1-3, 2010, pp. 455-462. doi:10.1016/j.jhazmat.2009.09.074

[3] R. L. Yu, X. Yuan, Y. H. Zhao and X. L. Tu, "Heavy Metal Pollution in Intertidal Sediments from Quanzhou Bay," Journal of Environmental Sciences, Vol. 20, No. 6, 2008, pp. 664-669. doi:10.1016/S1001-0742(08)62110-5

[4] NRC (National Research Council), "Drinking Water and Public Health Safe Drinking Water Committee," National Academy Press, Washington DC, 1977.

[5] World Health Organization, "Guidelines for Drinking Water Quality,” Vol. 1, WHO, 1993, p. 52.

[6] V. C. Srivastava, I. D. Mall and I. M. Mishra, "Characterization of Mesoporous Rice Husk Ash (RHA) and Adsorption Kinetics of Metal Ions from Aqueous Solution onto RHA," Journal of Hazardous Materials, Vol. 134, No. 1-3, 2006, pp. 257-267.

doi:10.1016/j.jhazmat.2005.11.052

[7] J. A. Grout and C. D. Levings, "Effects of Acid Mine Drainage from an Abandoned Copper Mine, Britannia Mines, Howe Sound, British Columbia, Canada, on Transplanted Blue Mussels (Mytilus edulis)," Marine Environmental Research, Vol. 51, No. 3, 2001, pp. 265-288. doi:10.1016/S0141-1136(00)00104-5

[8] C. Lin, Y. Wu, W. Lu, A. Chen and Y. Liu, "Water Chemistry and Ecotoxicity of an Acid Mine Drainage-Affected
Stream in Subtropical China during a Major Flood Event," Journal of Hazardous Materials, Vol. 142, No. 1-2, 2007, pp. 199-207. doi:10.1016/j.jhazmat.2006.08.006

[9] R. Y. Ning, “Arsenic Removed by Reverse Osmosis," Desalination, Vol. 143, No. 3, 2002, pp. 237-241. doi:10.1016/S0011-9164(02)00262-X

[10] G. U. Von, "Oxidation Kinetics and Product Formation," Water Research, Vol. 37, No. 7, 2003, pp. 1443-1467. doi:10.1016/S0043-1354(02)00457-8

[11] X. Chen, G. Chen and P. L. Yue, "Novel Electrode System for Electroflotation of Wastewater," Environmental Science and Technology, Vol. 36, No. 4, 2002, pp. 778-783. doi:10.1021/es011003u

[12] Z. Hu, L. Lei, Y. Li and Y. Ni, "Chromium Adsorption on High-Performance Activated Carbons from Aqueous Solution," Separation and Purification Technology, Vol. 31, No. 1, 2003, pp. 13-18. doi:10.1016/S1383-5866(02)00149-1

[13] Z. Reddad, C. Gerente, Y. Andres, J. F. Thibault and P. Le Cloirec, "Cadmium and Lead Adsorption by Natural Polysaccharide in MF Membrance Reactor: Experimental Analysis and Modeling," Water Research, Vol. 37, No. 16, 2003, pp. 3983-3991. doi:10.1016/S0043-1354(03)00295-1

[14] W. Ciesielski, C. Y. Lii, M. T. Yen and P. Tomasik, "Internation of Starch with Salt of Metals from the Transition Groups," Carbohydrate Polymers, Vol. 51, No. 1, 2003, pp. 47-56. doi:10.1016/S0144-8617(02)00108-X

[15] H. Hyung and J. H. Kim, "A Mechanistic Study on Boron Rejection by Sea Water Reverse Osmosis Membranes," Journal of Membrane Science, Vol. 286, No. 1-2, 2006, pp. 269-278. doi:10.1016/i.memsci.2006.09.043

[16] G. A. Waychunas, C. C. Fuller and J. A. Davis, "Surface Complexation and Precipitate Geometry for Aqueous Zn(II) Sorption on Ferrihydrite I: X-Ray Absorption Extended Fine Structure Spectroscopy Analysis," Geochimica et Cosmochimica Acta, Vol. 66, No. 7, 2002, pp. 1119-1137. doi:10.1016/S0016-7037(01)00853-5

[17] D. Pérez-Quintanillaa and I. Del Hierroa, "Mesoporous Silica Functionalized with 2-Mercaptopyridine: Synthesis, Characterization and Employment for $\mathrm{Hg}(\mathrm{II})$ Adsorption," Microporous Mesoporous Materials, Vol. 89, No. 1-3, 2006, pp. 58-68. doi:10.1016/j.micromeso.2005.10.012

[18] R. De Pablo, M. L. Chávez and M. Abatal, "Adsorption of Heavy Metals in Acid to Alkaline Environments by Montmorillonite and Ca-Montmorillonite," Chemical Engineering Journal, Vol. 171, No. 3, 2011, pp. 1276-1286. doi:10.1016/j.cej.2011.05.055

[19] M. A. Zenasni, S. Benfarhi, A. Merlin, S. Molina, B. George and B. Meroufel, "Adsorption of $\mathrm{Cu}(\mathrm{II})$ on Maghnite from Aqueous Solution: Effects of $\mathrm{pH}$, Initial Concentration, Interaction Time and Temperature," Natural Science, Vol. 10, No. 11, 2012, pp. 856-868. doi:10.4236/ns.2012.411114

[20] I. Ikhsan, B. B. Johson, J. D. Wells and M. J. Angove, "Adsorption of Aspartic Acid," Journal of Colloid and Interface Science, Vol. 273, No. 1, 2004, pp. 1-5. doi:10.1016/j.jcis.2004.01.061 
[21] A. Sari and O. Isildak, "Adsorption Properties of Stearic Acid onto Untreated Kaolinite," Bulletin of The Chemical Society of Ethiopia, Vol. 20, 2006, pp. 1-9. doi:10.4314/bcse.v20i2.61410

[22] M. J. Angove, B. B. Johson and J. D. Wells, "Adsorption of Cadmium(II) on Kaolinite," Colloids and Surfaces A: Physicochemical and Engineering Aspects, Vol. 126, No. 2-3, 1997, pp. 137-147. doi:10.1016/S0927-7757(96)03990-8

[23] K. O. Adebowale, I. E. Unuabonah and B. I. Olu-Owolabi, "The Effect of Some Operating Variables on the Adsorption of Lead and Cadmium Ions on Kaolinite Clay," Journal of Hazardous Materials, Vol. 134, No. 1-3, 2006, pp. 130-139. doi:10.1016/i.jhazmat.2005.10.056

[24] K. G. Bhattacharyya and S. S. Gupta, "Kaolinite and Montmorillonite as Adsorbents for $\mathrm{Fe}(\mathrm{III}), \mathrm{Co}(\mathrm{II})$ and $\mathrm{Ni}$ (II) in Aqueous Medium," Applied Clay Science, Vol. 41, No. 12, 2008, pp. 1-9. doi:10.1016/j.clay.2007.09.005

[25] K. G. Bhattacharyya and S. S. Gupta, "Kaolinite, Montmorillonite, and Their Modified Derivatives as Adsorbents for Removal of $\mathrm{Cu}(\mathrm{II})$ from Aqueous Solution," $\mathrm{Se}$ paration and Purification Technology, Vol. 50, No. 3, 2006, pp. 388-397. doi:10.1016/j.seppur.2005.12.014

[26] S. S. Gupta and K. G. Bhattacharyya, "Interaction of Metal Ions with Clays: I. A Case Study with Pb(II)," Applied Clay Science, Vol. 30, No. 3-4, 2005, pp. 199-208. doi:10.1016/j.clay.2005.03.008

[27] Y. Yukselen and A. Kaya, "Suitability of Methylene Blue Test for Surface Area, Cation Exchange Capacity and Swell Potential Determination of Clayey Soils," Engineering Geology, Vol. 102, No. 1-2, 2008, pp. 38-45. doi:10.1016/i.enggeo.2008.07.002

[28] S. Wang, Z. Nan, Y. Li and Z. Zhao, "The Chemical Bonding of Copper Ions on Kaolin from Suzhou, China," Desalination, Vol. 228, 2009, pp. 97-107.

[29] M. L. Granizo, M. T. B. Varela and S. Martinez-Ramirez, "Alkali Activation of Metakaolins: Parameters Affecting Mechanical, Structural and Microstructural Properties," Journal of Materials Science, Vol. 42, No. 9, 2007, pp. 2934-2943. doi:10.1007/s10853-006-0565-y

[30] A. G. S. Cristóbal, R. Castelló, M. A. M. Luengo and C. Vizcayno, "Zeolites Prepared from Calcined and Mechanically Modified Kaolins: A Comparative Study," Applied Clay Science, Vol. 49, No. 3, 2010, pp. 239-246. doi:10.1016/j.clay.2010.05.012

[31] E. Galan, P. Aparicio, A. Miras, K. Michailidis and A. Tsirambides, "Technical Properties of Compounded Kaolin Sample from Griva (Macedonia, Greece)," Applied Clay Science, Vol. 10, No. 6, 1996, pp. 477-490. doi:10.1016/0169-1317(95)00041-0

[32] M. Q. Jiang, X. Y. Jin, X. Q. Lu and Z. L. Chen, “Adsorption of $\mathrm{Pb}(\mathrm{II}), \mathrm{Cd}(\mathrm{II}), \mathrm{Ni}(\mathrm{II})$ and $\mathrm{Cu}(\mathrm{II})$ onto Natural Kaolinite Clay," Desalination, Vol. 252, No. 1-3, 2010, pp. 33-39. doi:10.1016/j.desal.2009.11.005

[33] A. Sari, M. Tuzen, D. Citak and M. Soylak, "Equilibrium, Kinetic and Thermodynamic Studies of Adsorption of $\mathrm{Pb}(\mathrm{II})$ from Aqueous Solution onto Turkish Kaolinite Clay," Journal of Hazardous Materials, Vol. 149, No. 2,
2007, pp. 283-291. doi:10.1016/j.jhazmat.2007.03.078

[34] I. Langmuir, "The Adsorption of Gases on Plane Surfaces of Glass, Mica and Platinum," Journal of the American Chemical Society, Vol. 40, No. 9, 1918, pp. 1361-1403. doi:10.1021/ja02242a004

[35] M. O Zacar and I. A. S. Engil, "Equilibrium Data and Process Design for Adsorption of Disperse Dyes onto Alunite," Environment Geology, Vol. 45, No. 6, 2004, pp. 762-768. doi:10.1007/s00254-003-0936-5

[36] H. Freundlich, "Über die Adsorption in lösungen," Zeitschrift für Physikalische Chemie (Leipzig), Vol. 57, 1906, pp. 385-470.

[37] E. Eren, "Removal of Copper Ions by Modified Unye Clay, Turkey," Journal of Hazardous Materials, Vol. 159, No. 2-3, 2008, pp. 235-244. doi:10.1016/j.jhazmat.2008.02.035

[38] A. Sari, M. Tuzen and M. Soylak, "Adsorption of Pb(II) and Cr(III) from Aqueous Solution on Celtek Clay," Journal of Hazardous Materials, Vol. 144, No. 1-2, 2007, pp. 41-46. doi:10.1016/j.jhazmat.2006.09.080

[39] A. Sari, M. Tuzen, D. Citak and M. Soylak, “Adsorption Characteristics of $\mathrm{Cu}(\mathrm{II})$ and $\mathrm{Pb}(\mathrm{II})$ onto Expanded Perlite from Aqueous Solution," Journal of Hazardous Materials, Vol. 148, No. 1-2, 2007, pp. 387-394. doi:10.1016/j.jhazmat.2007.02.052

[40] D. Xu, X. L. Tan, C. L. Chen and X. K. Wang, “Adsorption of $\mathrm{Pb}$ (II) from Aqueous Solution to MX-80 Bentonite: Effect of $\mathrm{pH}$, Ionic Strength, Foreign Ions and Temperature," Applied Clay Science, Vol. 41, No. 1-2, 2008, pp. 37-46. doi:10.1016/j.clay.2007.09.004

[41] A. Günay, E. Arslankaya and I. Tosun, "Lead Removal from Aqueous Solution by Natural and Pretreated Clinoptilolite: Adsorption Equilibrium and Kinetics," Journal of Hazardous Materials, Vol. 146, No. 1-2, 2007, pp. 362371. doi:10.1016/j.jhazmat.2006.12.034

[42] S. Veli and B. Alyüz, "Adsorption of Copper and Zinc from Aqueous Solutions by Using Natural Clay," Journal of Hazardous Materials, Vol. 149, No. 1, 2007, pp. 226233. doi:10.1016/j.jhazmat.2007.04.109

[43] P. Ding, K. L. Huang, G. Y. Li, Y. F. Liu and W. W. Zeng, "Kinetics of Adsorption of $\mathrm{Zn}$ (II) Ion on Chitosan Derivatives," International Journal of Biological Macromolecules, Vol. 39, No. 4-5, 2006, pp. 222-227. doi:10.1016/j.ijbiomac.2006.03.029

[44] C. H. Weng and C. P. Huang, "Adsorption Characteristics of $\mathrm{Zn}(\mathrm{II})$ from Dilute Aqueous Solution by Fly Ash," Colloids and Surfaces A: Physicochemical and Engineering Aspects, Vol. 247, No. 1-3, 2004, pp. 137-143. doi:10.1016/j.colsurfa.2004.08.050

[45] S. Lagergren, "Zur Theorie der Sogenannten Adsorption gel Osterstoffe Kungliga Svenska vetenskapsakademiens," Handlingar, Vol. 24, 1898, pp. 1-39.

[46] Y. S. Ho, "Citation Review of Lagergren Kinetic Rate Equation on Adsorption Reactions," Scientometrics, Vol. 59, No. 1, 2004, pp. 171-177. doi:10.1023/B:SCIE.0000013305.99473.cf

[47] Y. S. Ho, "Selection of Optimum Sorption Isotherm," Carbon, Vol. 42, No. 10, 2004, pp. 2115-2116. 
doi:10.1016/j.carbon.2004.03.019

[48] C. Quintelas, H. Figueiredo and T. Tavares, "The Effect of Clay Treatment on Remediation of Diethylketone Contaminated Wastewater: Uptake, Equilibrium and Kinetic Studies," Journal of Hazardous Materials, Vol. 186, No. 2-3, 2011, pp. 1241-1248. doi:10.1016/j.jhazmat.2010.11.131

[49] S. C. Tsai, S. Ouyang and C. N. Hsu, "Sorption and Diffusion Behavior of Cs and Sr on Jih-Hsing Bentonite," Applied Radiation and Isotopes, Vol. 54, No. 2, 2001, pp. 209-215. doi:10.1016/S0969-8043(00)00292-X

[50] Y. S. Ho, "Review of Second-Order Models for Adsorption Systems," Journal of Hazardous Materials, Vol. 136, No. 3, 2006, pp. 681-689. doi:10.1016/j.jhazmat.2005.12.043

[51] D. Wen, Y. S. Ho and X. Tang, "Comparative Sorption Kinetic Studies of Ammonium onto Zeolite," Journal of Hazardous Materials, Vol. 133, No. 1-3, 2006, pp. 252256. doi:10.1016/i.jhazmat.2005.10.020

[52] Y. S. Ho and G. McKay, "Pseudo-Second Order Model for Sorption Processes," Process Biochemistry, Vol. 34, No. 5, 1999, pp. 451-465. doi:10.1016/S0032-9592(98)00112-5

[53] B. Meroufel, O. Benali, M. Benyahia, Y. Benmoussa and M. A. Zenasni, "Adsorptive Removal of Anionic Dye from Aqueous Solutions by Algerian Kaolin: Characteristics, Isotherm, Kinetic and Thermodynamic Studies," Journal of Materials and Environmental Science, Vol. 4, No. 3, 2013, pp. 482-491.

[54] M. A. Zenasni, S. Benfarhi, A. Merlin, S. Molina, B. George and B. Meroufel, "Adsorption of Nickel in Aqueous Solution onto Natural Maghnite," Materials Sciences and Applications, Vol. 4, No. 2, 2013, pp. 153-161. doi:10.4236/msa.2013.42018

[55] A. Safa Özcan, B. Erdem and A. Özcan, "Adsorption of Acid Blue 193 from Aqueous Solutions onto Na-Bentonite and DTMA-Bentonite," Journal of Colloid and Interface Science, Vol. 280, No. 1, 2004, pp. 44-54. doi:10.1016/j.jcis.2004.07.035

[56] N. Caliskan, A. Riza Kul, S. Alkan, E. G. Sogut and I. Alacabey, "Adsorption of Zinc(II) on Diatomite and Manganese-Oxide-Modified Diatomite: A Kinetic and Equilibrium Study," Journal of Hazardous Materials, Vol. 193, No. 15, 2011, pp. 27-36. doi:10.1016/j.jhazmat.2011.06.058

[57] L. Guo, C. M. Sun, G. Y. Li, C. Liu and C. Ji, "Thermodynamics and Kinetics of Zn(II) Adsorption on Crosslinked Starch Phosphates," Journal of Hazardous Materials, Vol. 161, No. 1, 2009, pp. 510-515. doi:10.1016/j.jhazmat.2008.04.003

[58] M. K. Jhaa, R. R. Upadhyay, J. C. Lee and V. Kumar, "Treatment of Rayon Waste Effluent for the Removal of $\mathrm{Zn}$ and Ca Using Indion BSR Resin," Desalination, Vol. 228, No. 1-3, 2008, pp. 97-107. doi:10.1016/j.desal.2007.08.010

[59] Y. Zhang, Y. Li, L. Q. Yang, X. J. Ma, L. Y. Wang and Z. F. Ye, "Characterization and Adsorption Mechanism of $\mathrm{Zn}^{2+}$ Removal by PVA/EDTA Resin in Polluted Water," Journal of Hazardous Materials, Vol. 178, No. 1-3, 2010, pp. 1046-1054. doi:10.1016/j.jhazmat.2010.02.046

[60] P. C. Mishra and R. K. Patel, "Removal of Lead and Zinc Ions from Water by Low Cost Adsorbents," Journal of Hazardous Materials, Vol. 168, No. 1, 2009, pp. 319-325. doi:10.1016/j.jhazmat.2009.02.026

[61] P. R. Puranik and K. M. Paknikar, "Influence of Co-Cations on Biosorption of Lead and Zinc-A Comparative Evaluation in Binary and Multimetal Systems," Bioresource Technology, Vol. 70, No. 3, 1999, pp. 269-276. doi:10.1016/S0960-8524(99)00037-1

[62] A. Ucer, A. Uyanik and S. F. Aygun, "Adsorption of $\mathrm{Cu}(\mathrm{II}), \mathrm{Zn}(\mathrm{II}), \mathrm{Mn}(\mathrm{II})$ and $\mathrm{Fe}(\mathrm{II})$ Ions by Tannic Acid Immobilized Activated Carbon," Separation and Purification Technology, Vol. 47, No. 3, 2006, pp. 113-118. doi:10.1016/j.seppur.2005.06.012

[63] S. R. Shukla and R. S. Pai, "Adsorption of $\mathrm{Cu}(\mathrm{II}), \mathrm{Ni}(\mathrm{II})$ and $\mathrm{Zn}(\mathrm{II})$ on Dye Loaded Groundnut Shells and Sawdust," Separation and Purification Technology, Vol. 43, No. 1, 2005, pp. 1-8. doi:10.1016/j.seppur.2004.09.003

[64] A. K. Meena, G. K. Mishra, P. K. Rai, C. Rajagopal and P. N. Nager, "Removal of Heavy Metal Ions from Aqueous Solutions Using Carbon Aerogel as an Adsorbents," Journal of Hazardous Materials, Vol. 122, No. 1-2, 2005, pp. 161-170. doi:10.1016/j.jhazmat.2005.03.024

[65] E. Pehlivan, S. Cetin and B. H. Yanik, "Equilibrium Studies for the Sorption of Zinc and Copper from Aqueous Solutions Using Sugar Beat Pulp and Fly Ash," Journal of Hazardous Materials, Vol. 135, No. 1-3, 2006, pp. 193199. doi:10.1016/j.jhazmat.2005.11.049

[66] S. Karabulut, A. Karabaka, A. Deaizbi and Y. Yurcim, "Batch Removal of Copper(II) and Zinc(II) from Aqueous Solutions with Low Rank Turkish Coals," Separation and Purification Technology, Vol. 18, No. 3, 2000, pp. 177184. doi:10.1016/S1383-5866(99)00067-2

[67] M. I. Kandah, "Zinc and Cadmium Adsorption on LowGrade Phosphate," Separation and Purification Technol$o g y$, Vol. 35, No. 1, 2004, pp. 61-70. doi:10.1016/S1383-5866(03)00131-X

[68] A. K. Bhattacharya, S. N. Mandal and S. K. Das, "Adsorption of $\mathrm{Zn}$ (II) from Aqueous Solution by Using Different Adsorbents," Chemical Engineering Journal, Vol. 123, No. 1-2, 2006, pp. 43-51. doi:10.1016/j.cej.2006.06.012

[69] Y. Li, Q. Yue and B. Gao, "Adsorption Kinetics and Desorption of $\mathrm{Cu}(\mathrm{II})$ and $\mathrm{Zn}$ (II) from Aqueous Solution onto Humic Acid," Journal of Hazardous Materials, Vol. 178, No. 1-3, 2010, pp. 455-461.

doi:10.1016/j.jhazmat.2010.01.103

[70] C. Pérez-Novo, D. Fernández-Calviño and A. BermúdezCouso, "Phosphorus Effect on Zn Adsorption-Desorption Kinetics in Acid Soils," Chemosphere, Vol. 83, No. 7, 2011, pp. 1028-1034. doi:10.1016/j.chemosphere.2011.01.064

[71] E. Katsou, S. Malamis, M. Tzanoudaki, K. Haralambous and M. Loizidou, "Regeneration of Natural Zeolite Polluted by Lead and Zinc in Wastewater Treatment Systems," Journal of Hazardous Materials, Vol. 189, No. 3, 2011, pp. 773-786. doi:10.1016/j.jhazmat.2010.12.061 
[72] L. Agouborde and R. Navia, "Heavy Metals Retention Capacity of a Non-Conventional Sorbent Developed from a Mixture of Industrial and Agricultural Wastes," Journal of Hazardous Materials, Vol. 167, No. 1-3, 2009, pp. 536544. doi:10.1016/j.jhazmat.2009.01.027 